\title{
CALCIUM-PHOSPHORUS METABOLISM AND CALCIUM-REGULATING HORMONES IN OSTEOPOROSIS WHICH ASSOCIATED WITH LIVER CIRRHOSIS
}

\section{IRYNA GOLOVACH ${ }^{1}$, ZINOVIJ MYTNYK ${ }^{2}$, DIANA VERSHYNINA ${ }^{2}$}

\section{${ }^{1}$ Clinical Hospital «Feofania», Kyiv, Ukraine \\ ${ }^{2}$ National Medical University, Ivano-Frankivsk, Ukraine}

\section{Objectives}

The fastest and most significant bone loss are occurring in patients with autoimmune hepatitis and primary biliary cirrhosis $[1 ; 5 ; 6 ; 7]$. When liver damage viral aetiologies opinions of investigators are not unanimous. Some studies indicate that presence of cirrhosis does not determine bone loss. In contrast, other authors point to the existence of interdependence between the major clinical symptoms of liver injury and impaired structural and functional state of bone tissue. Thus, the bone loss in primary biliary cirrhosis is associated with serum concentrations of gastrin and expressiveness of cholestasis; in viral hepatitis and cirrhosis - with a degree of disturbances of proteinsynthetic liver function, level of bilirubinemia, and cholinesterase activity cytolysis [2]. According to histological studies, osteoporosis is found in $21 \%$ of patients with chronic liver disease [3]. In primary biliary cirrhosis, according to DXA, osteoporosis is identified in $24 \%$ of patients in the lumbar spine and in $32 \%$ in the femur. A significant percentage of osteoporosis is observed in presence of a viral liver disease. Osteoporosis is diagnosed in $53 \%$ of patients with liver cirrhosis [6; 7]. Various researchers have found different percentage of patients with osteoporosis, but all emphasize a significant loss of bone mass and lower bone mineral density in presence of hepatitis and cirrhosis, which occurs 4 times more often than in a cohort of healthy individuals [4].

Chronic liver diseases (CLD) lead to an imbalance of bone remodeling, bone mass decrease with the development of hepatic osteodystrophy, which displays itself most often in osteoporosis. In development of structural and functional deficiency of bone an important role is played by calcium-phosphorus homeostasis and calcium-regulating hormones coherence, which include parathyroid hormone $(\mathrm{PTH})$ and active metabolites of vitamin D.

The aim of the study was to determine violations of mineral metabolism, the concentration of calciumregulating hormones, as well as to establish the influence of disturbances in these systems of osteoporosis associated with LC.

\section{Methods}

We observed 172 patients with liver cirrhosis (LC), the average age $-49,3 \pm 7,7$ years. The men were 108 $(62.8 \%)$, women - 64 (37.2\%). Duration of illness ranged from 8 months to 9 years, on average accounting for $6,4 \pm 1,7$ years. Bone mineral density (BMD) was determined by DXA "Challenger" (DMS, France). We also determined the serum concentration of calcium and phosphorus, urinary excretion, the level of PTH and 25-hydroxyvitamin D (25(OH)D).

\section{Results}

We found significant violations of the calciumphosphorus metabolism, changes in the $\mathrm{CRH}$, and reduced bone mineral density in patients with LC, but the severity of the imbalance depended on the severity of the disease and correlated with the main laboratory criteria of liver dysfunction. We observed decrease serum concentration of total and ionized calcium, as well as the expressive tendency to hypercalciuria.

The concentration of $25(\mathrm{OH}) \mathrm{D}$ was $9,88 \pm 4,36 \mathrm{ng} / \mathrm{ml}$ (in control $26,76 \pm 9,27 \mathrm{ng} / \mathrm{ml} ; \mathrm{P}<0,01$ ). The level of deficit depended on the degree of liver dysfunction. In the case of compensated of LC the level of $25(\mathrm{OH}) \mathrm{D}$ was $12,93 \pm 5,42 \mathrm{ng} / \mathrm{ml}$ and decompensated $4,53 \pm 1,22 \mathrm{ng} / \mathrm{ml}$ (a decrease of 2.8 times). It emphasizes that with abnormal liver function significantly affected the formation of this $25(\mathrm{OH}) \mathrm{D}$, ie mechanism of the first hydroxylation of vitamin $D$, which occurs in the liver. PTH level was elevated in a majority of patients. Serum concentrations of PTH were on average $82,2 \pm 5,3 \mathrm{pg} / \mathrm{ml}$ in patients with LC. It significantly changed at different degrees of disease activity and severity of hepatocellular insufficiency. In the compensation stage of LC the PTH level was $39,8 \pm 3,1 \mathrm{pg} / \mathrm{ml} \quad(P>0,05)$, with subcompensation $89,8 \pm 4,2 \mathrm{pg} / \mathrm{ml}(\mathrm{P}<0,05)$, decompensation 103,2 $\pm 11,7$ $\mathrm{pg} / \mathrm{ml}(\mathrm{P}<0,001)$. PTH correlated with bone mineral density of the radius and lumbar spine. Moreover, PTH concentration correlated with indicators that determine the degree of liver dysfunction: with prothrombin time $(r$ $=-0,41 ; P<0,01)$; containing albumin levels $(r=-0,48 ; P$ $<0,01)$, the concentration of total bilirubin $(r=0,36$; $P$ $<0,05)$; concentration of cholesterol $(r=-0,32 ; P<0,05)$.
We also conducted a correlation analysis between the concentration of PTH and BMD parameters of the lumbar spine and radius. A strong correlation was found between PTH and BMD of the distal radius $(r=-$ $0,58 ; P<0,01)$, and such correlation was characteristic for both patients with viral and alcoholic cirrhosis. For BMD of the lumbar spine, the correlation was less pronounced $(r=-0,51 ; P<0,01)$. Our results of increased concentrations of PTH in patients with LC are confirmed by literature. It is indicated that the concentration of PTH in CLD increased despite adequate replacement of vitamin $D$ deficiency and normal (or subnormal) serum levels of calcium [5; 7]. Researchers suggest that independent PTH secretion increase, which, in its turn, stimulates lack of vitamin D active metabolites and secondary hyperparathyroidism, is more common than diagnosed before manifestation of clinical signs of disease, and causes early loss of bone mass.

\section{Conclusions}

Thus, in patients with LC, violations of mineral metabolism with the emergence of resistant hypocalcemia, lack of vitamin $D$ active metabolites and development of secondary hyperparathyroidism, especially in severe liver dysfunction, are observed. The development of secondary hyperparathyroidism in a proportion of patients can cause disorders in remodeling processes, accelerated bone loss and formation of osteoporosis.

\section{References}

Chen C.C., Wang S.S., Jeng F.S., Lee S.D. Metabolic bone disease liver cirrhosis: is it parallel to the clinical severity of cirrhosis? J.Gastroenterol. Hepatol - 1996.- Vol. 11, № 5.- P. 417-421.

Goel V. Kar P. Hepatic osteodystrophy // Trop. Gastroenterol. - 2010. Vol. 31(2). - P.82-86.

López-Larramona G. Lucendo A.J., González-Castillo S. Tenias J.M. liver disease //World J. Hepatol - 2011. - Vol. 3(12) - P.300-307. Suzuki K., Arakawa Y. Chino S., Yagi K. Hepatic osteodystrophy // Nippon Rinsho. - 1998- Vol. 56 № 6. - P. 1604-1608.

Trautwein C. Possienke M. SchlitH H., Boker K.H., Hom R. Bone density Trautwein $\mathrm{C}$ Posm in patients with viral hepatis and

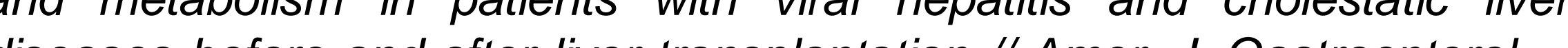
diseases be 05 , No 9. P. 2343-2351.

Tsuneoka K., Tameda Y., Takase K., Nakano T. Osteodystrophy in patients with chronic hepatitis and liver cirrhosis // J. Gastroenterol. - 1996. - Vol. 31, № 5.- P. 669-678.

Wariaghli G., Mounach A., Achemlal L., et al. Osteoporosis in chronic liver disease: a case-control study // Rheumatol. Int.- 2010. - Vol.30(7). P.893-899. 